\title{
FEMALE ONLINE PARTICIPATION IN THE BRAZILIAN PRESIDENTIAL CAMPAIGN
}

\author{
Readers' comments in two Portuguese newspapers as a case study
}

\author{
Autora: SILVA, Marisa Torres Da \\ Post-doctoral researcher in New University of Lisbon (Portugal) / CIMJ \\ marisatorresilva@hotmail.com
}

\begin{abstract}
The Internet encloses unambiguous possibilities of public communication and debate, by creating new spaces for political expression and participation. As a potential deliberative section, readers' comments in newspapers' websites constitute a domain enabling citizens to express their views on a particular issue, reacting specifically to a news piece and discussing it along with other readers as well.

From a gender perspective, studying the women's participation in online debates becomes increasingly relevant to understanding the social aspects of Internet use. Some studies have demonstrated, however, that gender differences in online communication tend to disfavour women: women send fewer messages, receive fewer responses and often aren't able to control the topic of discussion (Herring, 2000).

This paper intends to take the debate around the Brazilian presidential campaign as a case study of the possibility of a

In modern societies, the Internet encloses various possibilities of public communication and debate, by creating new spaces for political expression and participation. Citizens have therefore the opportunity for a more ac-tive involvement in deliberation processes within a very different interaction framework from the one that is provided by conventional media (Schultz, 2000; Chadwick, 2006; Esteves, 2007).
\end{abstract}

\begin{abstract}
"female" public sphere, attempting to analyse the way by which women discuss political issues online. Additionally, given the nature and characteristics of the main presidential candidates, our aim is also to understand whether questions about gender were important to the discussion or if the dichotomy male/female was suppressed in the public debate surrounding the campaign.

In order to fulfil these purposes, our research focuses on readers' on the Brazilian presidential campaign (SeptemberNovember 2010) in the online versions of two Portuguese newspapers, Público and Expresso.
\end{abstract}

\section{Key words}

Internet, readers' comments, media, participation, gender

\section{Introduction}

The more optimistic views about the Internet claim that access to its environment is universal and nonhierarchical, and it provides a noncoercive communication, helping to generate opinion within discussion processes; thus, Internet is seen by the majority of deliberative democracy's proponents as a space that promotes rational debate, from which deliberation is generated (Ferreira, 2010: 103). "Deliberation deno- 
tes a broad class of public communication, which is characterized by the attempt to provide some kind of justification of evidence, some kind of argumentative or evidential support for statements or judgments, explanations or proposals, some kind of anticipation of doubt, openness for questions and objections, recognition of fallibility" (Peters apud Gimmler, 2001: 29-30). Offering means for civic expression, Internet can act as a "sounding board" likely to affect political agents and other citizens (Ferreira, 2010: 105).

Moreover, the online environment can also stimulate the circulation of other discursive forms beyond rationalcritical argumentation, giving shape to a heterogeneous public space, either in terms of language and expression or in terms of subjects discussed (Esteves, 2003: 203). Indeed, the Internet is even likely to establish a different concept of "public" from the habermasian perspective (which is based in strict normative dichotomies such as public/private, universal/particular or reason/emotion), where we can see "the Public" as a work in progress, with more flexible frontiers with "the private" and, consequently, more open to new problems and issues that otherwise would not be acknowledged (2003: 204205).

The deliberative conception of politics is based on the articulation between the political agents and the general public - therefore, the public sphere represents the place where groups, associations, social movements and in-dividuals can connect with formal politics, in order to set the agenda and debate issues of collective concern (Silveirinha, 2004: 220). Here we can find a great diversity of fora where the exchange of information and opinion occurs. As an access mode to the public sphere, mainstream media have the possibility to expand those processes of opinion formation (2004: 229), making visible the problems that affect citizens - the incorporation of the Internet in its structures has certainly enlarged public debate, by promoting spaces where in-dividuals discuss ideas and arguments.

Several scholars argue that the Internet might serve to democratize the public sphere, although doubts remain about the extent to which these new forms of participation lead to a fruitful public debate or whether they actually offer more opportunities to citizens to question and challenge the power holders (Papa- charissi, 2002; Coleman \& Blumler, 2009; Dahlgren, 2011). Indeed, Robert Goodin argues that posting a comment on the Internet is not in itself deliberative:

There must also be uptake and engagement - other people must hear or read, internalize and respond for that public sphere activity to count as remotely deliberative (apud Crawford, 2009: 454).

Others point out that online political discussions are fragmented, dominated by a few, and too specific to live up to the Habermasian ideal of rational accord (Papacharissi, 2009: 10).

However, the Internet has been giving women more access to the public sphere, offering diverse participatory possibilities (Cerqueira et al., 2009: 104). In addition to the expansion of places where women may at least have the possibility of expression, the Internet allows individuals to reinvent their identity the "nonchosen" attributes (like gender or age) can stay out of "self presentation" and, consequently, staying anonymous or using nicknames appears to suggest a greater potential of nonconstrained communication (Silveirinha, 2004: 261), as a way to break down barriers, exclusions and silences (Harcourt apud Choudhury, 2009: 343) and stimulate a sense of empowerment. Anonymity can foster a more open debate, since the participants feel freer to express their opinions on-line (Wallace apud Ferreira, 2010: 110), which can encourage the expression of parts of the self repressed in offline interactions (Danet apud Dahlberg, 2001: 10) and remove the fear of being personally banned (De Keyser and Raeymaeckers, 2010: 9).

But if identity is fluid in the online environment, it is not certain that domination relations disappear in this space (Silveirinha, 2004: 262). In fact, Susan Herring argues that women and men have recognizably different styles in posting on the Internet, contrary to the claim that computermediated communication neutralizes distinctions of gender (Herring, 1994). In fact, users "give off" information about their gender unconsciously in interaction - the linguistic features that signal gender are much like face-to-face communication and include verbosity, assertiveness, politeness, and rudeness (Herring, 2000).

"The male style is characterized by adversariality: putdowns, strong, often contentions assertions, lengthy and/or frequent postings, selfpromotion, and sar- 
casm" (Herring, 1994). On the other hand, the femalegendered style distinguishes itself by "supportiveness" (expressions of appreciation, thanking, and attitudes that make other participants feel accepted and welcome) and "attenuation" (expressing doubt, apologizing, asking questions, and suggesting). Moreover, the same author found that women were more likely than men to post relatively short messages and to react aversively to aggression in online interaction, including falling silent and dropping out of groups (Herring, 2000), becoming passive observers (Dahlberg, 2001:14).

Herring concludes that gender differences in online communication tend to disfavour women: they post fewer messages, receive fewer responses from others, and often do not control the topic of the discussion except in groups where women make up a clear majority of participants (Herring, 2000).

The agonistic male style tends to be accepted and even encouraged in many online groups. The dominance of this style tends to impede women's participation more than men's, given that women are on the whole less accustomed and willing to engage in such forms of interaction (Dahlberg, 2001).
We can relate these assertions to James Bohman's concept of political poverty, which consists on

the inability of groups of citizens to participate effectively in the democratic process. The consequences of such poverty are twosided: public exclusion and political inclusion. On the one hand, politically impoverished groups cannot avoid public exclusion (...). On the other hand, such groups can not avoid political inclusion either (...). Their silence is turned into consent (...) (Bohman, 1997: 333).

Yet we argue that the online environment represents a sort of an extension of the existent inequalities in the offline political debates.

Here we are talking about informal impediments to participatory parity that can persist after everyone is formally and legally licensed to participate (...). Feminist research has documented a syndrome that many of us have observed in faculty meetings and other mixedsex deliberative bodies: men tend to interrupt women more than women interrupt men; men also tend to speak more than women, taking more turns and longer turns; and women's interventions are more often ignored or not responded to than men's (...). Even the language people use as they reason together usually favours one way of seeing things and discourages others (Fraser, 1992: 119).

Power enters in the discursive form, style and content, which means that minority groups tend to be excluded or silenced (Silveirinha, 2005: 24).

\section{Main purposes}

Having in mind the presented theoretical frame on female online participation, this article has two main objectives (O1 and $\mathrm{O} 2)$ :

O1: to analyse readers' comments that were part of the debate on the Brazilian presidential campaign as a case study of the possibility of a "female" public sphere, attempting to analyse how women discuss political issues online, particularly the deliberative processes of web use by women. How are they "speaking out" in public spaces through the media (McLaughlin, 1993: 615)?

O2: to understand whether questions about gender were important to the discussion, given the nature and characteristics of the main presidential candidates - two of them were women (Marina Silva and Dilma Rousseff), and eventually Dilma became the first female president of Brazil.

\section{Method}

In order to fulfil both purposes, we analysed the readers' comments in the news during the Brazilian presidential campaign (September-November 2010) in the online versions of two Portuguese newspapers, Público (a daily newspaper) and Expresso (a weekly newspaper). The event gained substantial journalistic coverage in Portugal (71 articles in Público online; and 60 news stories in Expresso online), due to the cultural proximity news value. We have focused only on the articles (6) that received the greatest number 
of comments in both websites; we have analysed 303 readers' comments (139 in Público and 164 in Expresso), using Nvivo, a qualitative and quantitative data analysis software.

This article integrates the project "Female Online Participation: redefining the public sphere", coordinated by Cláudia Álvares (Lusófona University, Portugal). The team has focused on a variety of online public spheres, ranging from the traditionally political to the more unconventionally political. The diverse case studies that integrated this project were subjected to a common analysis grid, with variables designed to define the discursive mode of the messages exchanged in the analysed fora, such as rationality of argumentation, civility or degree of rational legitimacy, among others. In this particular case, we chose to observe the readers' comments in the news focused on the Brazilian presidential campaign, within the focus already described. The unit analysis chosen for coding was the paragraph; each one was coded into one or more categories/subcategories. We also observed the word frequency among the readers' comments analysed.

The criteria to evaluate gender in readers' comments were the following: the name displayed by the user; and markers such as verbs, nouns, pronouns or articles that disclosed gender, even if the user used an ambiguous nickname.

\section{Main Findings}

\subsection{The candidates and gender discussion}

Dilma Rousseff was endorsed by (the very popular) president Lula da Silva as the candidate for the Worker's Party (PT) to be Brazil's president. She had worked in government as Lula's energy minister (where she was considered an "Iron Lady") and as his chief of staff. Lula had such a profound impact on Rousseff's campaign, making frequent public appearances and speeches of support (Lula even showed up at the campaign closure, in São Bernardo do Campo, where he had started his political career) - that much speculation was made about the political role that the outgoing leader would continue to play from behind the scenes. Rousseff was quick to acknowledge the influence of her predecessor when she became Brazil's first female president, stating, "I will be knocking on his door often, which, I'm sure, will always be open."1

Furthermore, despite this "happy ending" for Rousseff (and Lula), Dilma failed to be elected on the first round (October 3rd). This was due to allegations of corruption within her party and also to the unexpected success of candidate Marina Silva, Lula's former Minister of Environment and candidate for

\footnotetext{
${ }^{1}$ http://www.brazzil.com/articles/226-november-2010/10445dilma-wont-be-lulas-mouthpiece-shes-a-technocrat-with-a-steelydetermination.html
}

the Green Party (PV), which she joined on late 2009 after leaving the PT.

Indeed, the "alliance" between Lula and Dilma was highly perceived in the readers' comments analyzed. If we take a look at the word frequency, the most frequent words counted in comments were the following: "Dilma" (193), "Bra-sil" (188) and "Lula" (162), but also "Serra" (71), "Portugal" (69), "Brazilian" (53), "people" (53), "Marina" (46), "power" (43), "president" (42), "poverty" (30), "government" (29) and "party" (26). It is interesting to notice that "Lula" and "Dilma" had a very similar amount of word frequency, due to the fact that the former president and the president to be were seen as "one" candidate; José Serra and Marina Silva were much less mentioned in comments.

By observing the context in which the name "Dilma" was mentioned, we clearly see a tendency to associate the president to be with the former president and his/her party (PT) - either in terms of support, either in terms of opposition. Dilma's victory was mainly Lula's victory; in fact, few comments referred Rousseff's abilities and capacities as a (individual) political agent, even if we take comments that were clearly supportive of her victory .

This is even more evident in the comments that criticized Dilma, Lula and PT: terms like "puppet", "marionette", "pupil”, "goddaughter" or "creature” were used to pejoratively express the (current and 
future) dependence of Dilma towards Lula. Moreover, references to Marina Silva consisted on messages of support (focused on the fact that she managed to "force" a 2nd round; and the fact that she fought against Dilma-Lula), but also her alleged connections to IURD (Universal Church of the Kingdom of God). Thus we can say that while favourable messages on Marina Silva focused on her individual competences as a candidate (with the power to "defeat" Dilma-Lula), the majority of comments on Dilma Rousseff somewhat took away her individuality as a candidate and future president, by constantly associating her with the "real" winner, Lula da Silva. "As femininity and power are socially constructed as opponents, a tension between these spheres might occur when female politicians become media subjects" (Luenenborg et al., 2011: 58).

And was gender an issue debated on readers' comments about the Brazilian presidential election? In terms of word frequency, the words "women" and "woman" were barely mentioned in comparison to other terms (7 and 12 references each). The fact that Dilma and Marina were female candidates was not discussed from a gender viewpoint - Dilma and Marina were rarely mentioned as "women", but as candidates, from different ideological points of view (with some exceptions ${ }^{2}$ ). This may not be a surprise, as Dilma Rousseff skirted the issue off from her campaign - although in her first statement as a Presi-dent, Dilma promised to work towards greater gender equality in Brazil, in order to create an environment in which the election of a female head of state is no longer such an extraordinary accomplishment, but rather, as she explained, "something normal [that] can be repeated and expanded in companies, public institutions, and organi-zations that are representative of our entire society." However, Rousseff used the gender argument in her vic-tory speech, treating her gender as political asset and embracing her status as a woman (CoulombGully, 2011: 50) - "for the first time in Brazil, a woman will rule this country"; "I would like parents

\footnotetext{
2 "We, the women repressed and gagged by the patriarchal tyranny, [are celebrating Dilma's victory]"; "I hope that you [Dilma] do not disappoint men and make women proud".

3 http://www.brazzil.com/articles/226-november-2010/10445dilma-wont-be-lulas-mouthpiece-shes-a-technocrat-with-a-steelydetermination.html
}

who have daughters to look straight in their eyes and tell them: 'Yes, a woman can"'.

\subsection{Female participation and discussion}

Answering the second question of this paper - the presence/absence of female users in the discussion around the Brazilian presidential campaign, as well as the content and style of their participation - our analysis revealed that of the 303 comments, gender could only be determined in 233 , corresponding to 37 users (23.1\%). Of these, the overwhelming majority of comments' authors (218 comments/64 users $-72 \%$ ) were male, and only 15 posts were written by women ( 8 users $-4.9 \%$ ). Although this is a case study without representativeness ambitions, this may lead us to the conclusion that gender asymmetries also persist in cyberspace, which meets the existent literature review on this matter (Savicki et al., 1996; Herring, 2000; Dahlberg, 2001; De Keyser and Raeymaeckers, 2010).

In our analysis, we also verified that the $303 \mathrm{com}$ ments were posted by 104 unique participants, which amounts to an average of 2.9 comments per poster. Some users showed a peculiar regularity on their posting (in Público, a single user posted 31 comments; and in Expresso, several users posted more than 10 comments each; the frequency of posting was not very visible among the few female users - the maximum was a user that posted 4 comments).

These indicators show a striking similarity to empirical studies around other participation vehicles such as letters-to-the-editor in press (Raeymaeckers, 2005; Silva, 2009), which also demonstrate the pres-ence of regular readers in the letter writing activity - as well as the overrepresentation of male contributors.

Lincoln Dahlberg underlines that, although theoretically all subscribers to a group have equal opportunity to post, in many groups a small number of participants are responsible for most posts, which leads to the monopolization of attention within online discourse by particular individuals and groups (Dahlberg, 2001: 13), posing questions about discursive equality and inclusion. We can relate fre- 
quent posters' domination (as well as gender asymmetries) to the research reported by Kitchen about the rea-sons given for non-posting:

reluctance to speak to unknown people, resistance to participate in a group formed prior to one's arrival, being unsure about disclosure of self, fear of participating wrongly or poorly expressing oneself, and fear of being evaluated and receiving negative criticism (apud Dahlberg, 2001: 17).

We may also relate the weak participation of female users to the characteristics of the comments itselves: we found a substantial amount of non-politeness in comments - which includes defamation, personal attacks to other users and other behaviours such as the use of All-Caps or sarcasm (143 references $5.9 \%$ ). In the total of comments posted by women, non-politeness was only coded 5 times. Moreover, the category "critique to another" (user or, for ins- tance, a Politian) was one of the most coded in our sample, which suggests a very "aggressive" exchange of ideas in what respects the debate around the Brazilian presidential elections.

Almost every comment posted by female users was coded under the category "conversational response" (replies to other posts). Accordingly, this category was the most frequently coded $(27.1 \%$ - 611 references) within the overall categories. This may show the interactivity that readers' comments as a vehicle for participation may entail, as a dynamic space of ideas and arguments exchange. Although the existent literature review argues that female users receive fewer responses from others (Herring, 2000), our analysis shows that 4 (out of 15) com-ments posted by women were replied by other users.

\section{Conclusions}

Our case study about readers' comments about the Brazilian presidential campaign shows that male users may have "political advantages" towards women: although the Internet presents itself as an anonymous medium that can render gender invisible (gender-blind), gender disparity persists, posing questions to claims of gender-free equality in cyberspace. We presented two possible answers to this situation: the online environment extends the inequalities that define offline political debates; and women may be unwilling to participate in a space dominated by certain users (monopolization of attention) and aggres-sive/rude behaviours .

Regarding the conclusions we took from our study, we thus must ask how women can take advantage of new media developments in order to actively seek to gain influence in online fora, individually and collectively. In that sense, we argue that mainstre- am media should make an effort to moderate readers' comments in order to avoid the presence of non-politeness and disrespectful behaviours - possibly opening the door to a greater (and better) female po-litical participation.

However, the contingencies inherent to a case study (lack of representativeness and focus on the readers' comments on a particular event, in two Portuguese newspapers) don't allow us to go further in our answering to the questions posed by this article. Despite the referred limitations, this case study may permit us to proceed in the research of this subject, establishing indicators for a more extensive analysis of female participation via online media, namely with a comparative component (different countries and cultures, different media, different participation?). 


\section{References}

- Bohman, James y Rehg, William (eds.) (1997): Deliberative democracy: essays on reason and politics. London/Cambridge, The MIT Press.

- Cerqueira, Carla, Ribeiro, Luísa Teresa y Cabecinhas, Rosa (2009): "Mulheres \& blogosfera: contributo para o estudo da presença feminina na 'rede'”, en Ex Aequo n 19, pp. 111-128.

Chadwick, Andrew (2006): Internet politics: states, citizens, and new communication technologies. New York, Oxford University Press.

- Choudhury, Naziat (2009): “The question of empowerment: women's perspective on their Internet use", en Gender Technology and Development $n^{\circ} 13$ (3), pp. 341-363.

- $\quad$ Coleman, Stephen y Blumler, Jay G. (2009): The Internet and democratic citizenship. Theory, practice and policy. Cambridge, Cambridge University Press.

- Coulomb-Gully, Marlène (2011): “Women’s time has come: an archaeology of French Female Presidential Candidates - from Arlette Laguiller (1974) to Ségolène Royal (2007)”, en Gendered Transformations. Theory and practice on gender and media. Bristol \& Chicago, Intellect, pp. 43-55.

- Crawford, Ewan (2009): “A new sort of democracy?: The opinion pages in the Scottish daily quality press”, en Journalism n ${ }^{\circ} 10$, pp. 451-472.

- Dahlberg, Lincoln (2001): “Computermediated communication and the public sphere: a critical analysis”, en Journal of Computer-Mediated Communication $\mathrm{n}^{\mathrm{o}} 7$ (1).

- Dahlgren, Peter (2011): "As culturas cívicas e a Internet: para uma contextualização da participação política”, en Media \& Jornalismo n ${ }^{\circ} 18$ (10), pp. 11-30.

- $\quad$ Esteves, João Pissarra (2003): Espaço público e democracia. Lisboa, Edições Colibri.

- Esteves, João Pissarra (2007): “Os novos media na perspectiva da democracia deliberativa: sobre redes e tecnologias de informação e comunicação", en Espaços públicos, poder e comunicação. Porto, Edições Afrontamento, pp. 209-224.
- $\quad$ Ferreira, Gil (2010): "Internet e deliberação. A discussão política em fóruns online”, en Media \& Jornalismo $\mathrm{n}^{\mathrm{o}} 16$ (1), pp. 99-114.

- $\quad$ Fraser, Nancy (1992): "Rethinking the public sphere: a contribution to the critique of actually existing democracy”, en Habermas and the public sphere. Cambridge, Massachusetts, The MIT Press.

- Gimmler, Antje (2001): "Deliberative democracy, the public sphere and Internet", en Philosophy and Social Criticism no 27 (4), pp. 21-39.

- $\quad$ Herring, Susan (1994): “Gender differences in computer-mediated communication: bringing familiar baggage to the new frontier", paper presented at the American Library Association annual convention, Miami.

- Herring, Susan (2000): "Gender differences in CMC: findings and implications", en The CPR Newsletter $n^{\circ} 18$ (1).

- Keyser, Jeroen De y Raeymaeckers, Karin (2010): "Bottom-up or going down? The journalistic value of open online feedback opportunities", paper presented in the IAMCR Convention, Braga, Portugal.

- Luenenborg, Margreth, Roeser, Jutta, Maier, Tanja y Mueller, Kathrin (2011): "Gender analysis of mediated politics in Germany", en Gendered Transformations. Theory and practice on gender and media. Bristol \& Chicago, Intellect, pp. 57-74.

- McLaughlin , Lisa (1993): "Feminism, the public sphere, media and democracy", en Media, Culture \& Society n ${ }^{\circ} 15$, pp. 599-620.

- $\quad$ Papacharissi, Zizi (2002): "The virtual sphere: the internet as a public sphere”, en New Media Society $n^{\circ} 4$ (1), pp. 9-27.

- $\quad$ Papacharissi, Zizi (2009): "The virtual sphere 2.0: the internet, the public sphere and beyond", en Handbook of Internet Politics. London, Routledge.

- Raeymaeckers, Karin (2005): “Letters to the editor: a feedback opportunity turned into a marketing tool", en European Journal of Communication $n^{\circ} 20$ (2), pp. 199-221.

- Savicki, Victor, Lingenfelter, Dawn y Kelley, Merle (1996): “Gender language style and composition 
groups in Internet discussion groups", en Journal of Computer-Mediated Communication n ${ }^{\circ} 2$ (3).

- $\quad$ Schultz, Tanjev (2000): "Mass media and the concept of interactivity: an exploratory study of online forums and reader email”, en Media, Culture \& Society $n^{\circ} 22$, pp. 205-221.

- Silva, Marisa Torres da (2009): “As cartas dos leitores na imprensa portuguesa: uma forma de comunicação e debate do público”. PhD Thesis, New University of Lisbon.

- Silveirinha, Maria João (2004): Identidades, media e política: o espaço comunicacional nas democracias liberais. Lisboa, Livros Horizonte.

- Silveirinha, Maria João (2005): “Democracia deliberativa e reconhecimento: repensar o espaço público”, en Comunicação e política. Covilhã, Editora Universidade da Beira Interior.

\section{Forma de Citación}

SILVA, Marisa Torres Da: Female online participation in the brazilian presidential campaign. Readers' comments in two Portuguese newspapers as a case study. Revista Communication Papers, No 2, páginas 23 a 30. Departamento de Filología y Comunicación de la Universidad de Girona. Recuperado el de de 2 de: http://www.communicationpapers.es 